\title{
BMJ Open Awareness, knowledge and attitudes towards cardiopulmonary resuscitation among people with and without heart disease relatives in South China: a cross- sectional survey
}

\author{
Yun Teng, ${ }^{1}$ Yunxuan Li, ${ }^{2}$ Liya Xu, ${ }^{3}$ Fanyu Chen, ${ }^{1}$ Hailiu Chen, ${ }^{2}$ Ling Jin, ${ }^{2}$ \\ Jimei Chen, ${ }^{1}$ Jingjing Huang (D) , ${ }^{2}$ Gang $X u^{1}$
}

To cite: Teng $Y$, Li Y, Xu L, et al. Awareness, knowledge and attitudes towards cardiopulmonary resuscitation among people with and without heart disease relatives in South China: a crosssectional survey. BMJ Open 2020;10:e041245. doi:10.1136/ bmjopen-2020-041245

- Prepublication history and additional material for this paper is available online. To view these files, please visit the journal online (http://dx.doi.org/10. 1136/bmjopen-2020-041245).

YT and YL contributed equally.

YT and YL are joint first authors.

Received 05 June 2020

Revised 25 November 2020

Accepted 30 November 2020

A Check for updates

(C) Author(s) (or their employer(s)) 2020. Re-use permitted under CC BY-NC. No commercial re-use. See rights and permissions. Published by BMJ.

For numbered affiliations see end of article.

\section{Correspondence to}

Dr Jingjing Huang;

hjjing@mail.sysu.edu.cn and

Dr Gang Xu;

xuganghjj@163.com

\section{ABSTRACT}

Objectives To assess the awareness, knowledge and attitudes towards cardiopulmonary resuscitation (CPR) among relatives of people with and without heart disease and their influence in South China.

Design This is a cross-sectional survey. Logistic regression was used to evaluate the demographic factors associated with CPR training, learning and knowledge.

Setting The study was conducted in two hospitals, the largest cardiovascular institute and the largest eye care centre in South China.

Participants Healthy individuals who accompanied their relatives with heart disease to the outpatient department of cardiovascular disease and systemically healthy patients who came for regular ophthalmic examination and had no relatives with heart disease were consecutively recruited for the study. A total of 1644 respondents with heart disease relatives and 813 respondents without heart disease relatives completed the survey.

Results Thirty three per cent of respondents never heard of CPR and only $11 \%$ had received CPR training. Factors associated with a higher rate of CPR training were higher level of education and income $(p<0.001)$. Most respondents stated that CPR training was necessary and would like to learn CPR. However, only one-third considered it beneficial to perform CPR as a layperson. In addition, healthcare respondents $(p<0.001)$, younger $(p<0.05)$ and more educated respondents $(p<0.001)$ earned higher scores on the knowledge of CPR skills. Only 5.3\% had perfect scores on a CPR skills test. Notably, respondents with relatives suffering from heart disease had significantly less training experience and CPR knowledge than those without $(p<0.001)$.

Conclusions Although the attitudes towards learning CPR are very positive, there was a lack of knowledge on this topic among the general public. This study demonstrates an urgent need to boost awareness and training in CPR in South China, especially among people whose relatives have heart disease.

\section{INTRODUCTION}

Cardiac arrest is one of the leading causes of death worldwide and predominantly affects
Strengths and limitations of this study

- This is the first study to investigate an association between cardiopulmonary resuscitation (CPR) awareness and whether respondents have relatives with heart disease or not.

- Factors influencing CPR training, learning and knowledge were shown in the current study. These findings provide insights and strategies to improve layperson's response to cardiac arrest through public education campaigns.

- Surveys in hospitals may lead to sampling bias, limiting its generalisability. However, it may still lead to useful information that helps direct public health resources.

- The nature of cross-sectional survey may lead to recall bias.

patients with underlying heart disease. ${ }^{1}$ The global incidence of out-of-hospital cardiac arrest is 30.0 to 97.1 per 100000 person-years. ${ }^{2}$ From 1978 to 2016, the average incidence of cardiac arrest in China was 40.7 per 100000 person-years and the total mortality and morbidity rate were as high as $96.0 \% .^{3}$ Most cases of cardiac arrests are associated with previously diagnosed cardiovascular disease. Heart disease remains the predominant cause compared with non-cardiac causes. ${ }^{14}$ Studies have shown that the risks of death and anoxic brain injury of cardiac arrest victims decreased when bystander cardiopulmonary resuscitation (CPR) was performed before emergency medical services. ${ }^{5}$ However, the reported rate of bystander CPR was $55.2 \%$ in England, compared with less than $6 \%$ in China. ${ }^{6}$ The low rate of CPR means that sudden out-ofhospital cardiac arrest patients are denied a timely rescue. Most cardiac arrests occur at home $(74.5 \%$ in Beijing, China; $83.3 \%$ in 
Table 1 Sociodemographic characteristics of the respondents with and without heart disease relative

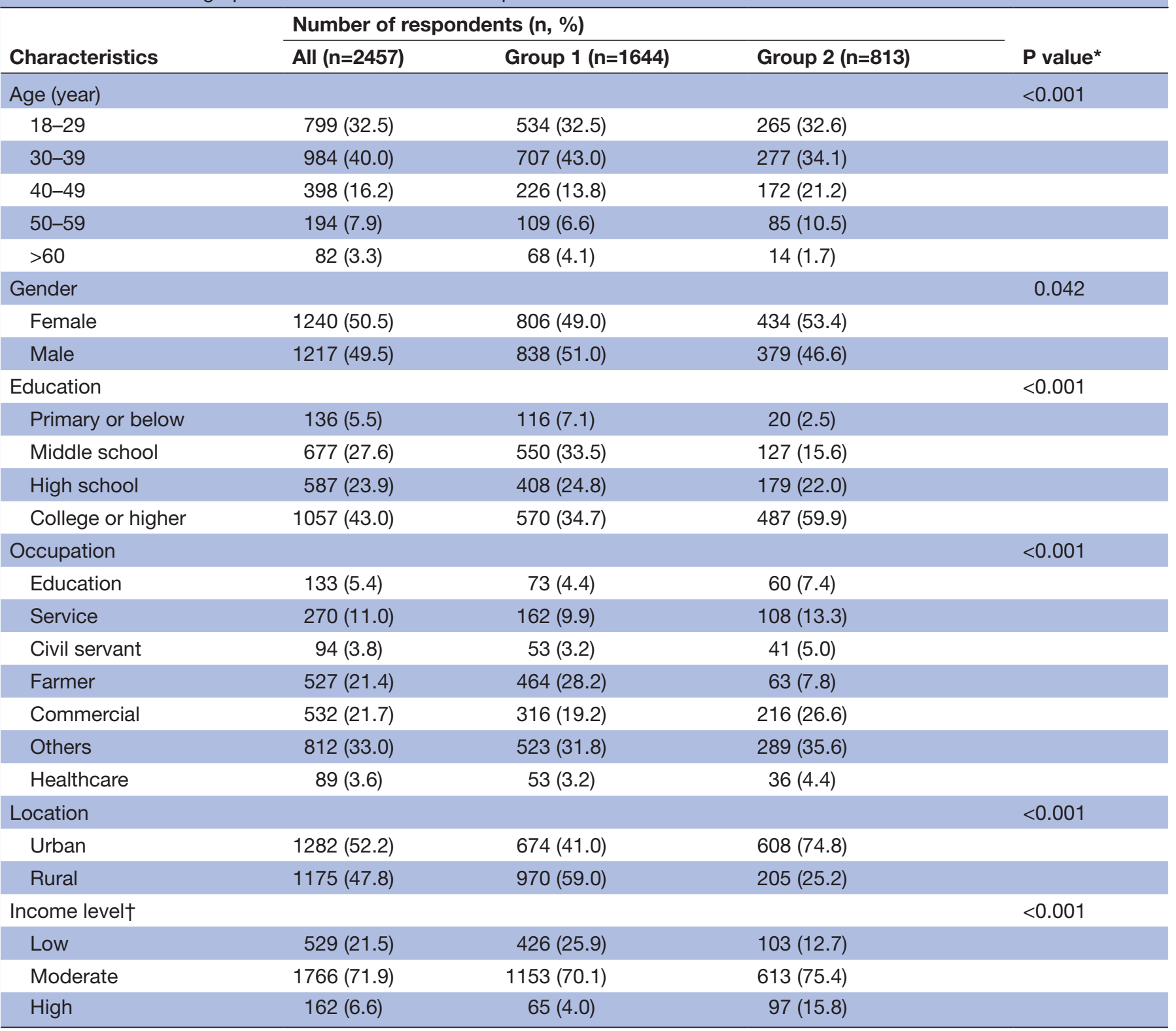

Group 1: relatives of patients with heart disease, group 2: relatives of patients without heart disease.

${ }^{*}$ All $\mathrm{P}$ values between the two groups were obtained using $\chi^{2}$ test.

†Low, less than $\$ 5,000 /$ year; moderate, $\$ 5,000$ /year to $\$ 50,000 /$ year; high, more than $\$ 50,000$ /year (according to China household finance survey in 2017).

England), and more than half are witnessed. ${ }^{47}$ If these witnesses have CPR capabilities, survival rates of cardiac arrest patients may increase significantly.

Previous studies have reported the awareness of CPR among laypersons in different countries. ${ }^{8-11}$ However, no research focused on the difference between family members of patients with and without heart disease. In the current study, we investigated the awareness, knowledge and attitudes towards CPR among relatives of patients with heart disease versus those without relatives suffering from the ailment in southern China. The results may add useful insights and provide strategies to promote broader adaptation of CPR among the general public.

\section{METHOD}

\section{Subjects and methods}

A cross-sectional survey was conducted from December 2018 to December 2019. The first arm of the study consisted of healthy individuals who accompanied their relatives with heart disease to the outpatient department of cardiovascular disease in Guangdong Provincial People's Hospital, the largest cardiovascular institute in South China (Group 1). The second arm included systemically healthy patients of the Zhongshan Ophthalmic Centre, the largest eye centre in South China, for routine examination and had no known relatives with heart disease (Group 2). Consecutive participants were at least 18 years 
Table 2 Additional sociodemographic characteristics of the patients with heart disease

\begin{tabular}{lc}
\hline Characteristics & $\begin{array}{c}\text { Number of respondents/ } \\
\text { patients (n=1644, \%) }\end{array}$ \\
\hline Responders' relation with the patients \\
\hline Parent & $375(22.8)$ \\
Spouse & $174(10.6)$ \\
Children & $877(53.4)$ \\
Sibling & $76(4.6)$ \\
Friend & $142(8.6)$ \\
Heart diseases of the patients & \\
\hline CHD & $1016(61.8)$ \\
VHD & $258(15.7)$ \\
CAD & $75(4.6)$ \\
Aortic dissection & $54(3.3)$ \\
Arrhythmia & $39(2.4)$ \\
\hline HBP & $56(3.4)$ \\
Unclear & $104(6.3)$ \\
\hline Others & $42(2.6)$ \\
\hline
\end{tabular}

Number of clinic visits of the patients

\begin{tabular}{cc}
1 & $463(28.2)$ \\
$2-3$ & $582(35.4)$ \\
$>4$ & $599(36.4)$ \\
Number of surgeries of the patients \\
\hline 0 & $139(8.5)$ \\
1 & $1199(72.9)$ \\
$2-3$ & $102(6.2)$ \\
$>4$ & $14(0.9)$ \\
Unclear & $190(11.6)$ \\
\hline
\end{tabular}

CHD, congenital heart disease; VHD, valvular heart disease; CAD, coronary artery disease; HBP, hypertension.

old and had no psychological or psychiatric deficiencies. The sample size was calculated by software PASS V.16.0 (NCSS, LLC, USA). Group sample sizes of 1632 and 816 cases produced a two-sided $95 \%$ CI for the population OR of 0.150 when the estimated sample proportion 1 was 0.18 , the estimated sample proportion 2 was 0.04 and the sample OR was 0.20. All samples were reached. In each hospital, three trained interviewers conducted face-toface interviews using a standardised questionnaire, after informed consent was obtained from all participants. This study was approved by the Institutional Review Board of both hospitals and adhered to the tenets of the Declaration of Helsinki.

\section{Questionnaire design}

The design of the questionnaire was based on published literatures about CPR awareness, ${ }^{12-14}$ which is described as knowing and having knowledge of CPR among general public. Items in the first section of the questionnaire (10 questions about demographic characteristics) included gender, age, educational level, occupation, location of residence and income. Four additional questions about the types of cardiovascular diseases, the number of previous visits to the hospital and the number of surgical treatments of the patients with heart disease were collected only in the first arm of the study. Usually, the follow-up interval is 3-6 months in clinical work. So the participants were divided into three categories for further analysis according to the duration of suffering heart diseases: 3-6 months, 6-12 months and over 12 months. The second section consisted of 11 questions regarding CPR training (questions 1-3), willingness to learn CPR (questions 4, 6 and 11), attitude towards CPR learning (question 5) and CPR knowledge (question 7 to 10) (see online supplemental file 1). A total of four points were assigned to answers to questions 7-10 at the ratio of 1:1:1:1. Every correct answer was awarded one point while incorrect answers or answer as 'unclear' were graded zero. Thus, the total score ranged from 0 to 4 for these four questions. Respondents who earned the higher score were considered more knowledgeable about CPR. On completion, correct answers of question 7 to 10 were given to the participants for educational purposes.

Draft questionnaires were administered to 20 patients in a pilot survey in both hospitals before initiation.

\section{Statistical analyses}

All questionnaires were validated and verified. Those with incomplete or duplicate responses were excluded. Analyses were conducted using SPSS V.24.0 (IBM SPSS Statistics for Windows, V.24.0. IBM Armonk, New York, USA). We compared the distribution of data between the two hospitals using $\chi^{2}$ test. Univariable and multivariable logistic regression analyses were used to detect the factors (having vs not having relatives with heart disease, gender, age, education, occupation, location, income level, relation to patient, number of prior clinic visits and number of surgeries for cardiovascular disease) impacting respondents' knowledge, and willingness and attitude towards learning CPR. $\chi^{2}$ test was used to examine the difference of CPR knowledge scores between trained and untrained respondents. Ordinal logistic regression analysis was used to investigate factors affecting knowledge of CPR. All variables with $\mathrm{p}<0.05$ in the univariable regression models were included in the multivariable regression analysis. Significant level was at $\mathrm{p}<0.05$.

\section{Participant and public involvement}

Participants and the public were not involved in the design or planning of the study. The study had no patient advisers. Participants were not involved in recruiting other participants or conduct of the study. Outcomes were self-reported by participants according to questionnaires. The study results are not planned to be disseminated to the participants. 
A

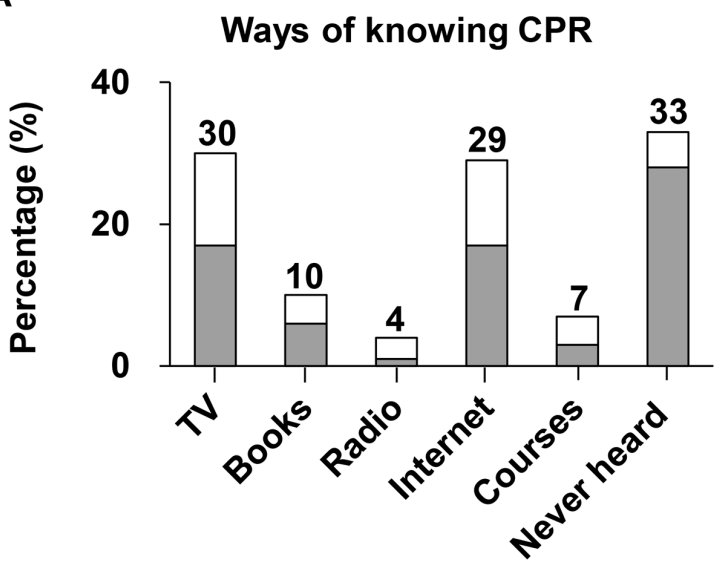

B

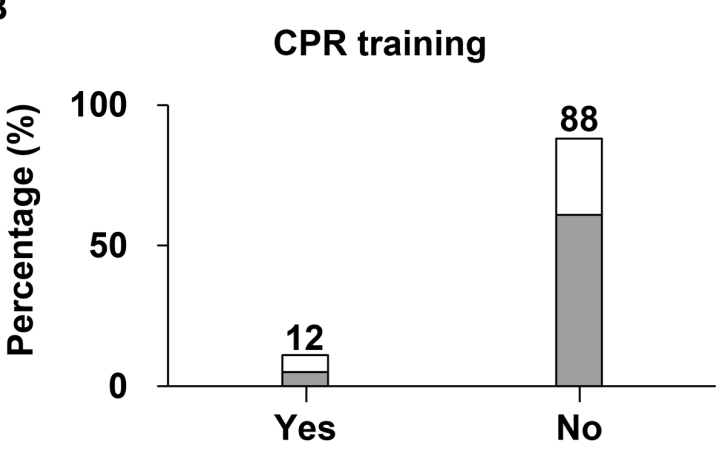

C

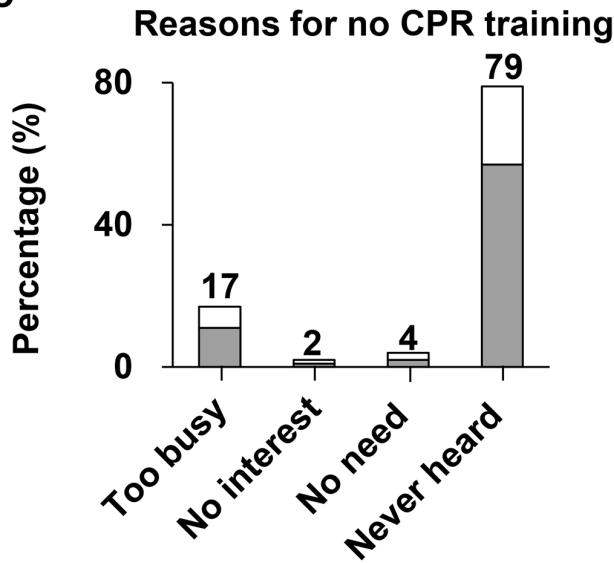

D

Preferred places for CPR training

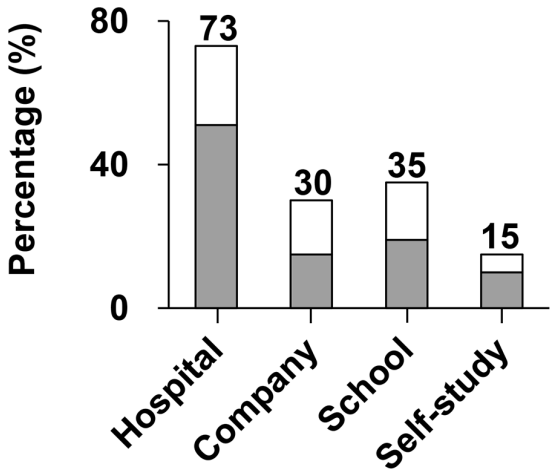

$\square$ Without heart disease relatives $\square$ With heart disease relatives

Figure 1 Status of CPR training. (A) Ways of getting to know CPR (multiple choices); (B) percentage of attending CPR training courses; (C) reasons for no CPR training (multiple choices); (D) preferred places for CPR training (multiple choices). The sum of percentage is labelled on the top of each bar. CPR, cardiopulmonary resuscitation.

\section{RESULTS}

Of 2557 questionnaires distributed in total, 2457 (96.1\%) questionnaires were completed and valid. Among the completed and valid questionnaires, $1644 \quad(66.9 \%)$ respondents affirmed that they had relatives with heart disease (group 1) while $813(33.1 \%)$ respondents did not (group 2). Basic demographic characteristics are presented in table 1.

Among the respondents, half of them were men and $72.6 \%$ were between 18 and 39 years old. Group 2 had higher education level, higher income and more commonly urban residents than group 1 . The additional information about the respondents and the patients with heart disease are shown in table 2.

\section{CPR training}

Thirty-three per cent of respondents (799/2457) never heard of CPR. The remaining two-third of respondents $(1658 / 2457)$ primarily knew about CPR was through television (30\%) and the internet (29\%) (figure 1A). Few respondents $(12 \%)$ reported attending CPR training courses (figure 1B). Regression analysis revealed that higher education attainment is associated with higher rate of CPR training, and not surprisingly healthcare professionals acquired more training than others $(p<0.001)$. In addition, lower income level was correlated with less CPR training experience (OR 0.47; 95\% CI 0.24 to $0.92 ; \mathrm{p}=0.028$ ). Surprisingly, group 1 respondents had less exposure to CPR training than their counterparts in group 2 (OR $0.54 ; 95 \% \mathrm{CI} 0.40$ to $0.73 ; \mathrm{p}<0.001$ ). The difference of relationship to patients with heart disease, the numbers of clinic visits and heart surgeries did not have a significant impact on CPR training of group 1 (p>0.05) (table 3).

Seventy-nine percent of people who had not takentraining courses indicated they have never heard of CPR courses (FIG. 1C). Thedesired venues where respondents wished to be trained (multiple choices) wereas follows: $73 \%$ in the hospital; $35 \%$ in the school; $30 \%$ in the company and $15 \%$ self-learning (FIG. 1D).

\section{Attitude towards CPR learning}

A vast majority of respondents considered knowledge about CPR necessary (90\%) and were willing to (92\%) attend courses (figure 2), especially among those younger than 50 years old $(\mathrm{p}<0.05)$. On the other hand, female 
Table 3 Logistic regression analysis of potential factors on receiving CPR training or not

\begin{tabular}{|c|c|c|c|c|}
\hline \multirow[b]{2}{*}{ Variable } & \multicolumn{2}{|c|}{ Univariable regression } & \multicolumn{2}{|c|}{ Multivariable regression* } \\
\hline & OR (95\% Cl) & $P$ value & OR (95\% Cl) & $P$ value \\
\hline \multicolumn{5}{|l|}{ Age (year) } \\
\hline $18-29$ & 2.67 (1.06 to 6.73$)$ & 0.038 & 2.52 (0.83 to 7.62$)$ & 0.103 \\
\hline $30-39$ & $1.96(0.78$ to 4.94$)$ & 0.155 & 2.08 (0.69 to 6.26$)$ & 0.195 \\
\hline $40-49$ & $1.58(0.60$ to 4.15$)$ & 0.354 & $1.90(0.61$ to 5.94$)$ & 0.271 \\
\hline $50-59$ & $1.11(0.38$ to 3.21$)$ & 0.853 & $1.56(0.45$ to 5.44$)$ & 0.485 \\
\hline$>60$ & Reference & & Reference & \\
\hline Female sex & 1.01 (0.79 to 1.29$)$ & 0.933 & & \\
\hline \multicolumn{5}{|l|}{ Education } \\
\hline Primary or below & 0.03 (0.004 to 0.20$)$ & $<0.001$ & 0.10 (0.01 to 0.73$)$ & 0.023 \\
\hline Middle school & 0.13 (0.08 to 0.20$)$ & $<0.001$ & 0.31 (0.18 to 0.52$)$ & $<0.001$ \\
\hline High school & $0.29(0.20$ to 0.41$)$ & $<0.001$ & 0.47 (0.31 to 0.69$)$ & $<0.001$ \\
\hline College or higher & Reference & & Reference & \\
\hline \multicolumn{5}{|l|}{ Occupation } \\
\hline Education & 0.05 (0.03 to 0.10$)$ & $<0.001$ & 0.04 (0.02 to 0.08$)$ & $<0.001$ \\
\hline Service & 0.03 (0.01 to 0.05 ) & $<0.001$ & 0.04 (0.02 to 0.07 ) & $<0.001$ \\
\hline Civil servant & 0.07 (0.04 to 0.15$)$ & $<0.001$ & 0.06 (0.03 to 0.13$)$ & $<0.001$ \\
\hline Farmer & 0.00 (0.004 to 0.01$)$ & $<0.001$ & 0.03 (0.01 to 0.07$)$ & $<0.001$ \\
\hline Commercial & 0.03 (0.02 to 0.05$)$ & $<0.001$ & 0.03 (0.02 to 0.06$)$ & $<0.001$ \\
\hline Others & 0.03 (0.02 to 0.05$)$ & $<0.001$ & 0.04 (0.02 to 0.07 ) & $<0.001$ \\
\hline Healthcare & Reference & & Reference & \\
\hline \multicolumn{5}{|l|}{ Location } \\
\hline Urban & 2.97 (2.25 to 3.93$)$ & $<0.001$ & $1.27(0.90$ to 1.80$)$ & 0.176 \\
\hline Rural & Reference & & Reference & \\
\hline \multicolumn{5}{|l|}{ Income level† } \\
\hline Low & $0.18(0.10$ to 0.31$)$ & $<0.001$ & 0.47 (0.24 to 0.92$)$ & 0.028 \\
\hline Moderate & 0.58 (0.39 to 0.87 ) & 0.009 & 0.82 (0.52 to 1.29$)$ & 0.383 \\
\hline High & Reference & & Reference & \\
\hline \multicolumn{5}{|l|}{ Heart disease relative } \\
\hline Yes & 0.39 (0.31 to 0.50$)$ & $<0.001$ & 0.54 (0.40 to 0.73$)$ & $<0.001$ \\
\hline No & Reference & & Reference & \\
\hline \multicolumn{5}{|l|}{ Relation to patient } \\
\hline Parent & $1.95(0.82$ to 4.66$)$ & 0.132 & & \\
\hline Spouse & 2.06 (0.74 to 5.72$)$ & 0.166 & & \\
\hline Children & 1.24 (0.53 to 2.91$)$ & 0.620 & & \\
\hline Sibling & $1.25(0.35$ to 4.44$)$ & 0.728 & & \\
\hline Friend & Reference & & & \\
\hline \multicolumn{5}{|l|}{ Number of clinic visits } \\
\hline 1 & 1.04 (0.60 to 1.80$)$ & 0.900 & & \\
\hline $2-3$ & 1.00 (0.60 to 1.62$)$ & 0.963 & & \\
\hline$>4$ & Reference & & & \\
\hline \multicolumn{5}{|l|}{ Number of surgeries } \\
\hline 0 & 1.84 (0.67 to 5.06$)$ & 0.240 & & \\
\hline 1 & 1.92 (0.85 to 4.35$)$ & 0.116 & & \\
\hline $2-3$ & 2.68 (0.90 to 7.98$)$ & 0.076 & & \\
\hline
\end{tabular}


Table 3 Continued

\begin{tabular}{|c|c|c|c|c|}
\hline \multirow[b]{2}{*}{ Variable } & \multicolumn{2}{|c|}{ Univariable regression } & \multicolumn{2}{|c|}{ Multivariable regression* } \\
\hline & OR $(95 \% \mathrm{Cl})$ & $P$ value & OR $(95 \% \mathrm{Cl})$ & $P$ value \\
\hline$>4$ & $1.88(0.25$ to 14.12$)$ & 0.541 & & \\
\hline
\end{tabular}

*All variables with $\mathrm{p}<0.05$ in the univariable regression models were included in the multivariable regression analysis.

†Low, less than $\$ 5,000 /$ year; moderate, $\$ 5,000$ /year to $\$ 50,000$ /year; high, more than $\$ 50,000$ /year (according to China household finance survey in 2017).

CPR, cardiopulmonary resuscitation.

respondents (OR $0.74 ; 95 \%$ CI 0.59 to $0.93 ; \mathrm{p}=0.011$ ), those with lower education attainment $(\mathrm{p}<0.001)$, those whose occupation were 'farmer' (OR 0.26 ; $95 \%$ CI 0.08 to $0.87 ; \mathrm{p}=0.029$ ) or 'other' in the questionnaires (OR 0.23; $95 \%$ CI 0.07 to $0.75 ; \mathrm{p}=0.015$ ), and those who had only one visit to cardiac clinic (OR $0.71 ; 95 \%$ CI 0.50 to 0.99 ; $\mathrm{p}=0.046$ ) deemed CPR learning less necessary and were less willing to attend training courses.

However, only $32 \%$ of respondents felt that it is beneficial for a layperson to perform CPR, $28 \%$ of respondents considered it harmful, while the remaining were unsure (figure 3). Further regression analysis showed that respondents below middle school education level $(p<0.05)$ and in non-medical occupations $(\mathrm{p}<0.05)$ were less likely to believe in the value of CPR.

\section{Knowledge of CPR skill}

Only 5.3\% among all of the 2457 respondents attained perfect scores on the four questions testing the knowledge about CPR. Respondents with previous training in CPR had higher scores (median=3) than those without

\section{Without heart disease relatives}

\section{With heart disease relatives}

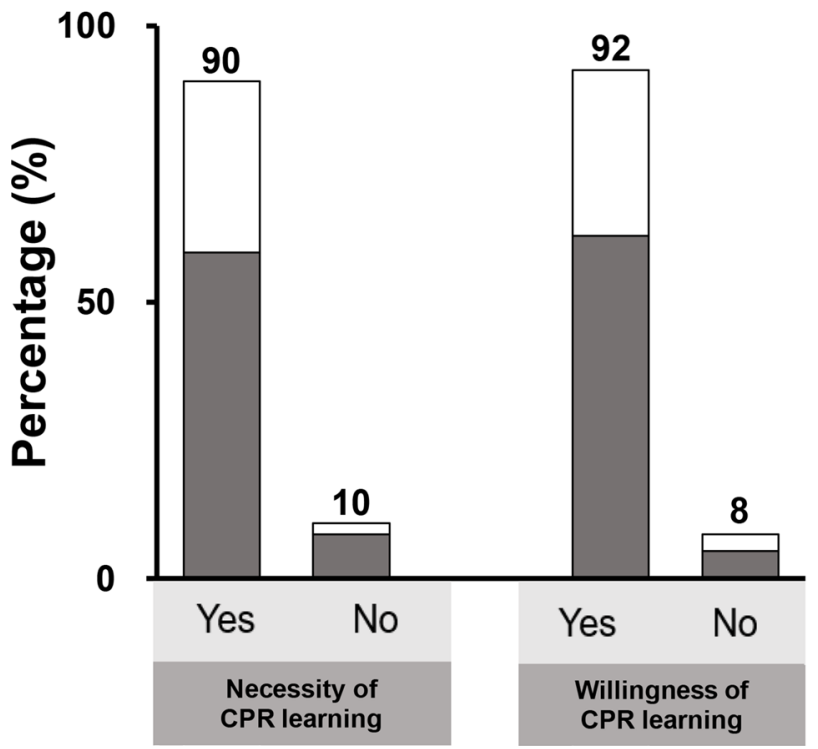

Figure 2 Necessity and willingness of CPR learning. The sum of percentage is labelled on the top of each bar. CPR, cardiopulmonary resuscitation. (median=1) $(\mathrm{p}<0.001$, table 4$)$, as did those younger than 50 years old $(\mathrm{p}<0.05)$, those with higher educational attainment $(\mathrm{p}<0.001)$ and people in the healthcare field $(\mathrm{p}<0.001)$ (table 5, figure 4).

However, group 1 received lower scores on CPR skills thangroup 2 (OR 0.56 ; $95 \%$ CI -0.48 to 0.66 ; $\mathrm{p}<0.001$ ). Among group 1, siblings ofheart disease patients scored lower (OR 0.48 ; $95 \%$ CI 0.28 to $0.81 ; \mathrm{p}=0.006$ ), while those whose relatives had never undergone the heart surgery scored higher(OR 1.81; 95\% CI 1.19 to 2.72; $\mathrm{p}=0.005$ ) (table 5).

\section{DISCUSSION}

CPR is an important part of the armamentarium for first aid responders. The general public is at a lack of CPR awareness and training experience. The current survey in a major metropolitan area showed that two-thirds of respondents have heard of CPR but very few have been trained. Previous studies showed the rates of brain damage and mortality among cardiac arrest patients decrease after CPR administration. ${ }^{5}$ Although most respondents stated that CPR is necessary and would like to learn about it, only $32 \%$ regarded performance of CPR by a layperson to be beneficial. Only $5.3 \%$ respondents knew the whole manifestations of cardiac arrest, content and golden time of CPR and the proper rate of chest compression to artificial ventilation. Education and income levels were

Without heart disease relatives

With heart disease relatives

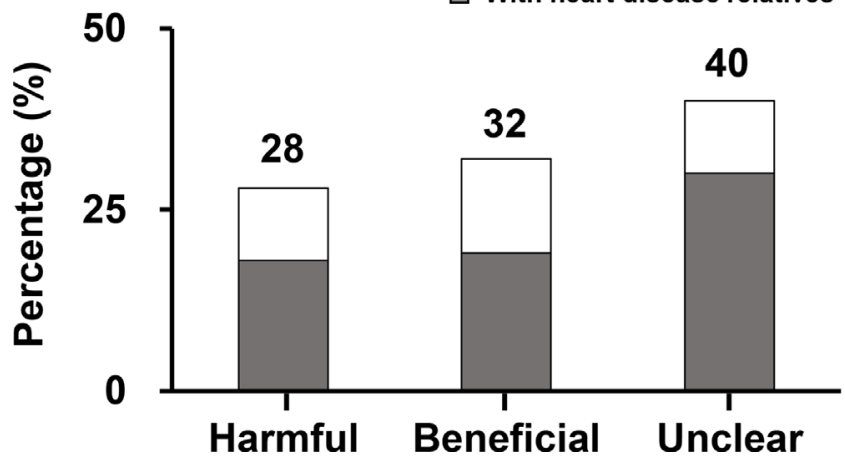

Figure 3 Attitude towards performing CPR by layperson. The sum of percentage is labelled on the top of each bar. $\mathrm{CPR}$, cardiopulmonary resuscitation. 
Table 4 Number of correct answers on knowledge of CPR skill in trained and untrained respondents

\begin{tabular}{llcc}
$\begin{array}{l}\text { Number of correct answers } \\
\text { on CPR knowledge }\end{array}$ & All (n=2457) & $\begin{array}{l}\text { With CPR training } \\
(\mathbf{n = 2 8 4 )}\end{array}$ & $\begin{array}{l}\text { Without CPR training } \\
(\mathbf{n = 2 1 7 3 )}\end{array}$ \\
\hline 0 & $581(23.6)$ & $5(1.8)$ & $576(26.5)$ \\
1 & $551(22.4)$ & $16(5.6)$ & $535(24.6)$ \\
2 & $714(29.1)$ & $80(28.2)$ & $634(29.2)$ \\
3 & $481(19.6)$ & $112(39.4)$ & $369(17.0)$ \\
4 & $130(5.3)$ & $71(25.0)$ & $59(2.7)$ \\
\hline
\end{tabular}

${ }^{*} \chi^{2}$ test was performed for comparison between groups.

$\mathrm{CPR}$, cardiopulmonary resuscitation.

strong positive predictors of the rate of CPR training and knowledge. However, to our surprise, respondents having relatives with heart disease had less training and knowledge about CPR. As far as we know, this is the first study to assess for an association between CPR awareness and training experience with or without heart disease among family members.

Only $12 \%$ of people had received CPR training in our study. Similar trends $(3 \%-25 \%)$ were observed in other cities in China. ${ }^{891516}$ In contrast, the rates of CPR training are higher in developed countries. Eighty-three per cent out of 9022 surveyed in the USA had received or are currently receiving CPR training. ${ }^{12}$ Fifty-six per cent of 1076 respondents in Australia reported receiving CPR training previously, with $22 \%$ trained less than a year. ${ }^{11}$

The difference in rate of CPR training between China and some developed countries may lie in differences in the promotion of the practice among the general public. In our study, 33\% had never heard of CPR, compared with only $9.9 \%$ surveyed in Australia. ${ }^{11}$ Among our respondents who are aware of CPR, most were introduced by TV or the internet, but $79 \%$ did not have access to training. As far as we are concerned, inactive promotion of CPR in China renders most information invisible to the public. Furthermore, because China does not mandate first-aid training for non-medical citizens, it fails to provide a platform for people to get informed. Previous studies in the USA have shown significant positive outcomes as a result of mandatory CPR training. ${ }^{17}$ Among 9022 participants, people in states with mandatory training programmes were $34 \%$ more likely to be currently trained than those in states without such programmes. ${ }^{17}$

We found that people who are better educated, engage in medical professions or are in higher income strata, and younger respondents have a greater chance of receiving CPR training. Similar correlation with greater educational attainment, higher income and younger age is found in other studies. ${ }^{811} 18$ It is reported that low education and low income are causal risk factors of cardiovascular disease. ${ }^{192}$ Therefore, living in rural areas with low level of education and low income was possible factors of low CPR training rate among relatives of patients with heart disease.
To our surprise, people with close relatives with heart disease had lower CPR training rates than those without. The more times of clinic visit, the longer duration of heart disease. Therefore, relatives of patients suffering heart disease have enough time to learn CPR but their participation and attainment of CPR training did not improve significantly. As patients' disease progresses, their relatives' attention paid to the learning of CPR continues to waver. Similar findings were worked out in America, which observed low participation rates of CPR training among family members of cardiac patients. ${ }^{21}$ The finding might reflect the lack of popularisation of CPR training from hospitals and other medical organisations to the target population. Although there are few evidence for improvement in patient outcomes from targeted Basic life support training for family members, ${ }^{22}$ pervious research showed that cardiac patients and their spouses had learning needs of CPR after an acute cardiac event. ${ }^{23}$ According to our survey, most responders would like to receive CPR training in hospitals and workplaces, but unfortunately they are still not widely available. Given the significant benefits, governments should actively promote CPR and provide funding for training programmes.

In the current study, although most participants have not received CPR training, a strong majority showed interest in learning. Ninety per cent regarded learning CPR as necessary and $92 \%$ were willing to take free training lessons. Our study revealed at least as much if not greater desire than other populations in or outside China. Among 2763 respondents in Wuhan, 77\% were willing to learn CPR. ${ }^{9}$ In Crimea, $52 \%$ of 384 respondents provided an affirmative answer to the question of whether they wish to attend CPR training. ${ }^{24}$ Ninety per cent of 947 university students in Saudi Arabia wanted to receive CPR training. ${ }^{25}$

In our survey, people aged below 50 tended to have a more positive attitude towards CPR. Similar trends were observed in Crimea, where people aged $\geq 60$ were mostly untrained and unwilling to learn CPR. ${ }^{24}$ Women were also found to be less willing to attend CPR courses. Because performing CPR can be physically demanding, elderly people and women may have difficulties performing this task and thus feel reluctant to learn. 
Table 5 Ordinal logistic regression analysis of potential factors on knowledge of CPR skill scores (scale from 0 to 4, 0 indicating lowest level, 4 indicating highest level)

\begin{tabular}{|c|c|c|c|c|}
\hline \multirow[b]{2}{*}{ Variable } & \multicolumn{2}{|c|}{ Univariable regression } & \multicolumn{2}{|c|}{ Multivariable regression* } \\
\hline & OR $(95 \% \mathrm{Cl})$ & $P$ value & OR $(95 \% \mathrm{Cl})$ & $P$ value \\
\hline \multicolumn{5}{|l|}{ Age } \\
\hline $18-29$ years & 3.34 (2.20 to 5.05$)$ & $<0.001$ & 2.44 (1.57 to 3.78 ) & $<0.001$ \\
\hline $30-39$ years & 2.30 (1.52 to 3.49$)$ & $<0.001$ & 1.76 (1.14 to 2,72$)$ & 0.010 \\
\hline $40-49$ years & 2.47 (1.60 to 3.82$)$ & $<0.001$ & 1.91 (1.21 to 3.00$)$ & 0.005 \\
\hline $50-59$ years & 1.81 (1.13 to 2.89 ) & 0.014 & 1.73 (1.06 to 2.83 ) & 0.027 \\
\hline$>60$ years & Reference & & Reference & \\
\hline Female sex & 1.28 (1.11 to 1.47$)$ & 0.001 & 1.14 (0.98 to 1.32 ) & 0.083 \\
\hline \multicolumn{5}{|l|}{ Education } \\
\hline Primary or below & 0.08 (0.06 to 0.12$)$ & $<0.001$ & 0.18 (0.12 to 0.26$)$ & $<0.001$ \\
\hline Middle school & 0.22 (0.18 to 0.26$)$ & $<0.001$ & 0.38 (0.30 to 0.47$)$ & $<0.001$ \\
\hline High school & 0.43 (0.36 to 0.52$)$ & $<0.001$ & 0.60 (0.49 to 0.73 ) & $<0.001$ \\
\hline College or higher & Reference & & Reference & \\
\hline \multicolumn{5}{|l|}{ Occupation } \\
\hline Education & 0.14 (0.08 to 0.23$)$ & $<0.001$ & 0.12 (0.08 to 0.21$)$ & $<0.001$ \\
\hline Service & 0.08 (0.05 to 0.12$)$ & $<0.001$ & 0.11 (0.07 to 0.18 ) & $<0.001$ \\
\hline Civil servant & 0.15 (0.09 to 0.26$)$ & $<0.001$ & 0.15 (0.09 to 0.26 ) & $<0.001$ \\
\hline Farmer & 0.03 (0.02 to 0.05$)$ & $<0.001$ & 0.09 (0.06 to 0.14$)$ & $<0.001$ \\
\hline Commercial & 0.11 (0.07 to 0.16$)$ & $<0.001$ & 0.12 (0.08 to 0.19$)$ & $<0.001$ \\
\hline Others & 0.09 (0.06 to 0.13$)$ & $<0.001$ & 0.12 (0.08 to 0.19$)$ & $<0.001$ \\
\hline Healthcare & Reference & & Reference & \\
\hline \multicolumn{5}{|l|}{ Location } \\
\hline Urban & 2.45 (2.11 to 2.83 ) & $<0.001$ & 1.18 (0.99 to 1.40$)$ & 0.062 \\
\hline Rural & Reference & & Reference & \\
\hline \multicolumn{5}{|l|}{ Income level $†$} \\
\hline Low & 0.27 (0.20 to 0.37$)$ & $<0.001$ & 0.78 (0.55 to 1.11$)$ & 0.156 \\
\hline Moderate & 0.61 (0.45 to 0.81$)$ & 0.001 & 0.96 (0.70 to 1.28$)$ & 0.763 \\
\hline High & Reference & & Reference & \\
\hline \multicolumn{5}{|c|}{ Heart disease relative } \\
\hline Yes & $0.38(0.33,0.45)$ & $<0.001$ & 0.56 (0.48 to 0.66$)$ & $<0.001$ \\
\hline No & Reference & & Reference & \\
\hline \multicolumn{5}{|c|}{ Relation to patient } \\
\hline Parent & 0.82 (0.58 to 1.16$)$ & 0.262 & 0.91 (0.63 to 1.31$)$ & 0.623 \\
\hline Spouse & 0.65 (0.44 to 0.97$)$ & 0.035 & 0.99 (0.65 to 1.51$)$ & 0.969 \\
\hline Children & 0.86 (0.63 to 1.19$)$ & 0.353 & 1.05 (0.75 to 1.50$)$ & 0.761 \\
\hline Sibling & $0.50(0.30$ to 0.84$)$ & 0.008 & 0.48 (0.28 to 0.81$)$ & 0.006 \\
\hline Friend & Reference & & Reference & \\
\hline \multicolumn{5}{|c|}{ Number of clinic visits } \\
\hline 1 & 0.67 (0.54 to 0.87$)$ & $<0.001$ & 0.83 (0.66 to 1.05$)$ & 0.114 \\
\hline $2-3$ & 0.88 (0.72 to 1.08$)$ & 0.231 & 0.99 (0.80 to 1.22$)$ & 0.940 \\
\hline$>4$ & Reference & & Reference & \\
\hline \multicolumn{5}{|c|}{ Number of surgeries } \\
\hline 0 & 2.33 (1.57 to 3.46$)$ & $<0.001$ & 1.81 (1.19 to 2.72$)$ & 0.005 \\
\hline 1 & 1.57 (1.19 to 2.08$)$ & 0.002 & 1.53 (1.14 to 2.05$)$ & 0.004 \\
\hline
\end{tabular}


Table 5 Continued

\begin{tabular}{|c|c|c|c|c|}
\hline \multirow[b]{2}{*}{ Variable } & \multicolumn{2}{|c|}{ Univariable regression } & \multicolumn{2}{|c|}{ Multivariable regression* } \\
\hline & OR $(95 \% \mathrm{Cl})$ & P value & OR $(95 \% \mathrm{Cl})$ & $P$ value \\
\hline $2-3$ & $1.43(0.92$ to 2.20$)$ & 0.107 & $1.48(0.94$ to 2.34$)$ & 0.088 \\
\hline Unclear & Reference & & Reference & \\
\hline
\end{tabular}

${ }^{*}$ All variables with $\mathrm{p}<0.05$ in the univariable regression models were included in the multivariable regression analysis.

†Low, less than $\$ 5,000$ /year; moderate, $\$ 5,000$ /year to $\$ 50,000 /$ year; high, more than $\$ 50,000$ /year (according to China household finance survey in 2017).

Despite respondents' enthusiasm in learning CPR, a solid majority $(68 \%)$ doubt the benefits of CPR when performed by non-medical professionals. Previous studies showed that fear of layperson CPR was general. Worrying about causing additional harm, contacting infectious diseases, lawsuits and the outcome of a failed resuscitation
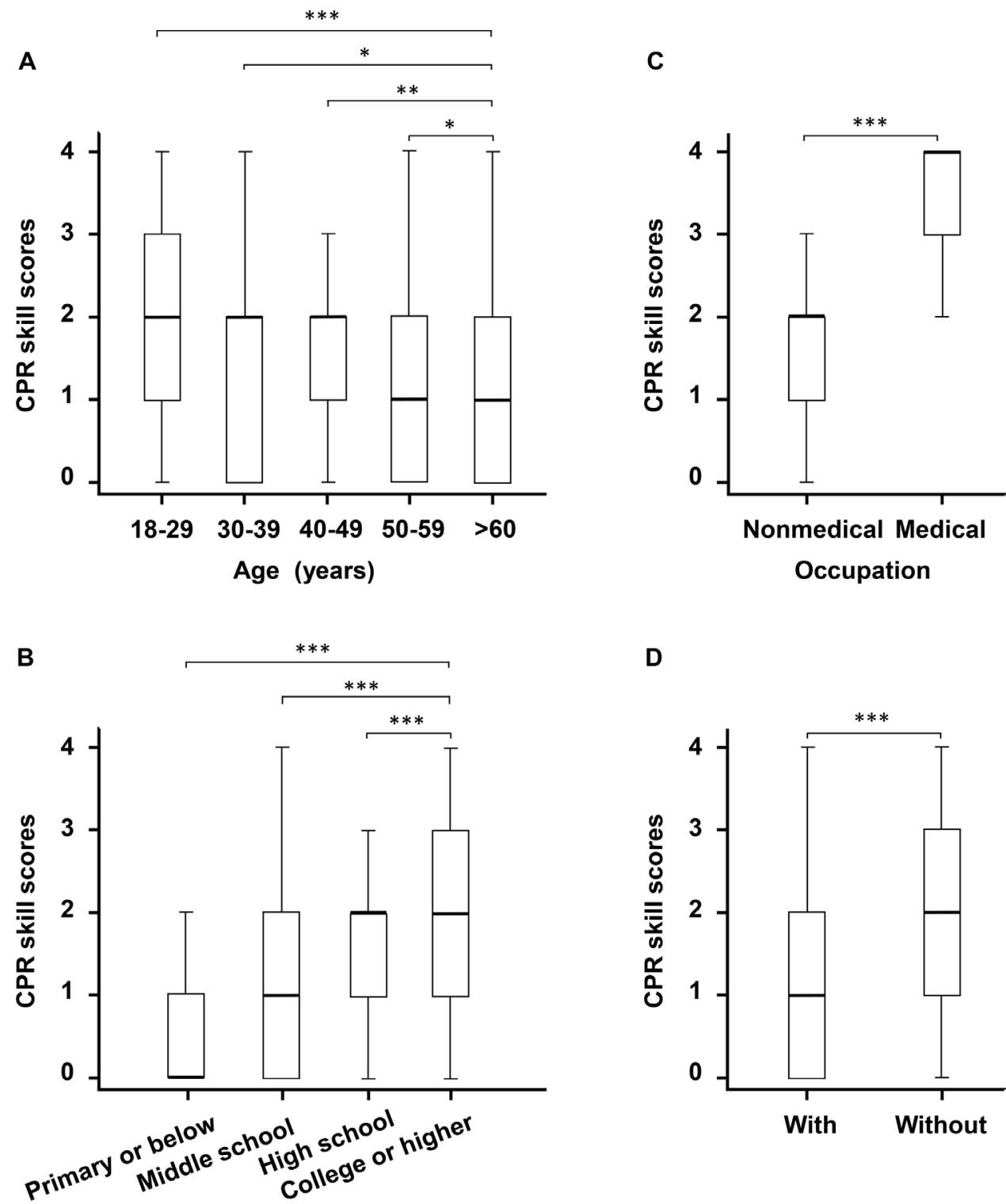

Education

Heart disease relatives

Figure 4 Effect on CPR skills by different factors. (A) Age; (B) education; (C) occupation; (D) having relative with heart disease. horizontal line within box, median; box, lower and upper quartiles; capped vertical lines, $95 \%$ confidence. ${ }^{\star} p<0.05$; ${ }^{\star *} p<0.01$; ${ }^{* * \star} \mathrm{p}<0.001$. CPR, cardiopulmonary resuscitation. 
might be the main barriers to CPR performance by a layperson. ${ }^{13} 2627$

The current survey revealed a general lack of knowledge about CPR, as only $5.3 \%$ of respondents correctly answered four questions. Such deficiencies are common not only in China, where the training rate is less than $1 \%,{ }^{28}$ but also in other countries. ${ }^{29-31}$ In addition, factors influencing CPR knowledge awareness include age, profession and education level in our study. Those who are younger, pursue healthcare professions, receive higher education tend to access more healthcare resources, and therefore are able to process more CPR knowledge.

Research indicates that medical students who had finished essential theoretical courses and training programmes should grasped all of the CPR knowledge, but the truth is that they did not achieve expected outcomes. Needless to say, non-medical professionals have little chance to attend professional training courses. ${ }^{32}$ Given the lack of CPR knowledge among the general public, mandatory intervention may ameliorate this problem. After a 5-year intervention in Korea, the percentage of respondents who received CPR education increased from $36.2 \%$ to $55.1 \%$, and scores on CPR performance increased from $1.6 \%$ to $11.7 \% .^{33}$ In a matched-pair study among untrained Nigerian students, the question about the recommended rate of chest compressions was answered correctly by $10.5 \%$ of the participants preintervention and $43.8 \%$ postintervention. The mean knowledge score increased from 1.9 to $11.4 .^{34}$

Therefore, public health campaigns appear to aid in disseminating knowledge and skills to the public, and such campaigns are urgently needed in countries where awareness of CPR is lacking. The government can also promote CPR on social media and television, where people consume such information most frequently according to our study.

Despite its contributions to our knowledge regarding the current situation of CPR among people whose relatives have heart disease, the study has some limitations. The nature of cross-sectional studies is limited that we cannot make any causal inferences and determinations of time course. And there may have been unmeasured confounding factors. In addition, some respondents had been trained CPR years ago, hence it was liable for recall difficulties.

\section{CONCLUSION}

Although the attitude towards learning CPR is very positive, only a small minority in our survey have had the proper training or knowledge. Also troubling, one-third of the respondents never heard of CPR, and people with close family members with heart disease who could potentially benefit the most from CPR were actually less likely to possess the necessary skills. Therefore, there is an urgent need to boost awareness and training in CPR in South China, especially among people with family members with heart disease.

\section{Author affiliations}

${ }^{1}$ Department of Cardiovascular Surgery, Guangdong Cardiovascular Institute, Guangdong Provincial People's Hospital, Guangdong Academy of Medical Sciences, Guangzhou, Guangdong, China

${ }^{2}$ State Key Laboratory of Ophthalmology, Zhongshan Ophthalmic Center, Sun YatSen University, Guangzhou, Guangdong, China

${ }^{3}$ Tufts University, Medford, Massachusetts, USA

Correction notice This article has been corrected since it first published. The provenance and peer review statement has been included.

Contributors $\mathrm{YT}, \mathrm{YL}$ and $\mathrm{LX}$ contributed to the study design, the data acquisition, the analysis and interpretation of data, drafted the first article and revised it critically; HC, FC, JC and JZ contributed to the data acquisition and revised the article critically; LJ contributed to the analysis and interpretation of data and revised the article critically. GX and JH conceived and designed the study, contributed to study analysis, interpretation of data and revised the article critically. All authors read and approved the final version for publication.

Funding This work was supported by the National Key Research and Development Program (2018YFC1002600), Guangdong Peak Project (DFJH201802), Guangdong Commissioner Program of Aid-Xinjiang (KTP20190285).

Competing interests None declared.

Patient consent for publication Not required.

Provenance and peer review Not commissioned; externally peer reviewed.

Data availability statement Data are available upon reasonable request. All data relevant to the study are included in the article or uploaded as supplementary information. All data collected during the study are included in the article or placed online as supplementary information. No additional data available.

Supplemental material This content has been supplied by the author(s). It has not been vetted by BMJ Publishing Group Limited (BMJ) and may not have been peer-reviewed. Any opinions or recommendations discussed are solely those of the author(s) and are not endorsed by BMJ. BMJ disclaims all liability and responsibility arising from any reliance placed on the content. Where the content includes any translated material, BMJ does not warrant the accuracy and reliability of the translations (including but not limited to local regulations, clinical guidelines, terminology, drug names and drug dosages), and is not responsible for any error and/or omissions arising from translation and adaptation or otherwise.

Open access This is an open access article distributed in accordance with the Creative Commons Attribution Non Commercial (CC BY-NC 4.0) license, which permits others to distribute, remix, adapt, build upon this work non-commercially, and license their derivative works on different terms, provided the original work is properly cited, appropriate credit is given, any changes made indicated, and the use is non-commercial. See: http://creativecommons.org/licenses/by-nc/4.0/.

ORCID iD

Jingjing Huang http://orcid.org/0000-0002-3009-8681

\section{REFERENCES}

1 Myat A, Song K-J, Rea T. Out-Of-Hospital cardiac arrest: current concepts. Lancet 2018;391:970-9.

2 Kiguchi T, Okubo M, Nishiyama C, et al. Out-Of-Hospital cardiac arrest across the world: first report from the International liaison Committee on resuscitation (ILCOR). Resuscitation 2020;152:39-49.

3 Feng X-F, Hai J-J, Ma Y, et al. Sudden cardiac death in mainland China. Circulation 2018;11:e006684.

4 Hawkes C, Booth S, Ji C, et al. Epidemiology and outcomes from out-of-hospital cardiac arrests in England. Resuscitation 2017;110:133-40.

5 Kragholm K, Wissenberg M, Mortensen RN, et al. Bystander efforts and 1-year outcomes in out-of-hospital cardiac arrest. $N$ Engl J Med 2017;376:1737-47.

6 YJ G, Cai MX, Sun KY, et al. The current status analysis of bystanderinitiated cardiopulmonary resuscitation for out-of-hospital cardiac arrest. Chinese J Crit Care Med 2015;5:477-80.

7 Shao F, Li CS, Liang LR, et al. Outcome of out-of-hospital cardiac arrests in Beijing, China. Resuscitation 2014;85:1411-7.

8 Li Y, Dong X-mei, Wang S-yong, et al. Consciousness and abilities on health emergency and the roles of emergency response among public at the communities. Zhonghua Liu Xing Bing Xue Za Zhi 2013;34:993-7. 
9 Chen Z-Q, Zhao Y, Lu Z-H, et al. Awareness and attitudes of Chinese students towards cardiopulmonary resuscitation. Emerg Med $\mathrm{J}$ 2010;27:907-10.

10 Hawkes CA, Brown TP, Booth S, et al. Attitudes to Cardiopulmonary Resuscitation and Defibrillator Use: A Survey of UK Adults in 2017. J Am Heart Assoc 2019;8:e008267.

11 Cartledge S, Saxton D, Finn J, et al. Australia's awareness of cardiac arrest and rates of CPR training: results from the heart Foundation's HeartWatch survey. BMJ Open 2020;10:e033722-7.

12 Blewer AL, Ibrahim SA, Leary M, et al. Cardiopulmonary resuscitation training disparities in the United States. J Am Heart Assoc 2017;6. doi:10.1161/JAHA.117.006124. [Epub ahead of print: 17 May 2017].

13 Shams A, Raad M, Chams N, et al. Community involvement in out of hospital cardiac arrest: a cross-sectional study assessing cardiopulmonary resuscitation awareness and barriers among the Lebanese youth. Medicine 2016;95:e5091.

14 Nord A, Svensson L, Hult $\mathrm{H}$, et al. Effect of mobile applicationbased versus DVD-based CPR training on students' practical CPR skills and willingness to act: a cluster randomised study. BMJ Open 2016;6:e010717.

15 Chen M, Wang Y, Li X, et al. Public knowledge and attitudes towards bystander cardiopulmonary resuscitation in China. Biomed Res Int 2017;2017:1-7.

16 Chair SY, Hung MSY, Lui JCZ, et al. Public knowledge and attitudes towards cardiopulmonary resuscitation in Hong Kong: telephone survey. Hong Kong Med J 2014;20:126-33.

17 Alexander TD, McGovern SK, Leary M, et al. Association of statelevel CPR training initiatives with layperson CPR knowledge in the United States. Resuscitation 2019;140:9-15.

18 Uehara R, Shinohara R, Akiyama Y, et al. Awareness of cardiopulmonary resuscitation among parents of 3-year-old children. Pediatr Int 2018;60:869-74.

19 Platz E, Scheatzle MD, Pepe PE, et al. Attitudes towards CPR training and performance in family members of patients with heart disease. Resuscitation 2000;47:273-80.

20 Tillmann T, Vaucher J, Okbay A, et al. Education and coronary heart disease: Mendelian randomisation study. BMJ 2017;358:j3542.

21 Rosengren A, Smyth A, Rangarajan S, et al. Socioeconomic status and risk of cardiovascular disease in 20 low-income, middleincome, and high-income countries: the prospective urban rura epidemiologic (pure) study. Lancet Glob Health 2019;7:e748-60.

22 Cartledge S, Bray JE, Leary M, et al. A systematic review of basic life support training targeted to family members of high-risk cardiac patients. Resuscitation 2016;105:70-8.
23 Cartledge S, Feldman S, Bray JE, et al. Understanding patients and spouses experiences of patient education following a cardiac event and eliciting attitudes and preferences towards incorporating cardiopulmonary resuscitation training: a qualitative study. J Adv Nurs 2018:74:1157-69.

24 Birkun A, Kosova Y. Social attitude and willingness to attend cardiopulmonary resuscitation training and perform resuscitation in the Crimea. World J Emerg Med 2018;9:237-48.

25 Owaid Alsharari A, Alduraywish A, Ali Al-Zarea E, et al. Current status of knowledge about cardiopulmonary resuscitation among the university students in the Northern region of Saudi Arabia. Cardiol Res Pract 2018;2018:1-9.

26 Sasson C, Haukoos JS, Bond C, et al. Barriers and facilitators to learning and performing cardiopulmonary resuscitation in neighborhoods with low bystander cardiopulmonary resuscitation prevalence and high rates of cardiac arrest in Columbus, $\mathrm{OH}$. Circ Cardiovasc Qual Outcomes 2013;6:550-8.

27 Savastano S, Vanni V. Cardiopulmonary resuscitation in real life: the most frequent fears of lay rescuers. Resuscitation 2011;82:568-71.

$28 \mathrm{Xu} \mathrm{F}$, Zhang Y, Chen Y. Cardiopulmonary resuscitation training in China: current situation and future development. JAMA Cardiol 2017;2:469-70.

29 Oteir AO, Almhdawi KA, Kanaan SF, et al. Cardiopulmonary resuscitation level of knowledge among allied health university students in Jordan: a cross-sectional study. BMJ Open 2019:9:e031725-9.

30 Aroor AR, Saya RP, Attar NR, et al. Awareness about basic life support and emergency medical services and its associated factors among students in a tertiary care hospital in South India. J Emerg Trauma Shock 2014;7:166-9.

31 Qara FJ, Alsulimani LK, Fakeeh MM, et al. Knowledge of nonmedical individuals about cardiopulmonary resuscitation in case of cardiac arrest: a cross-sectional study in the population of Jeddah, Saudi Arabia. Emerg Med Int 2019;2019:1-11.

32 Baldi E, Contri E, Bailoni A, et al. Final-Year medical students' knowledge of cardiac arrest and CPR: we must do more! Int $J$ Cardiol 2019;296:76-80.

33 Moon S, Ryoo HW, Ahn JY, et al. A 5-year change of knowledge and willingness by sampled respondents to perform bystander cardiopulmonary resuscitation in a metropolitan City. PLoS One 2019;14:e0211804-13.

34 Gabriel IO, Aluko JO. Theoretical knowledge and psychomotor skill acquisition of basic life support training programme among secondary school students. World J Emerg Med 2019;10:81-7. 